\title{
A Comparison of Four Geophysical Methods for Determining the Shear Wave Velocity of Soils
}

\author{
Neil Anderson', Thanop Thitimakorn', David Hoffman², Richard Stephenson², Ronaldo Luna² \\ Geological Sciences and Engineering, University of Missouri-Rolla, Rolla, Missouri \\ Civil, Architectural and Environmental Engineering, University of Missouri-Rolla, Rolla, Missouri
}

\begin{abstract}
Summary
The following four seismic methods were used to acquire shear wave velocity control at multiple test sites in the Poplar Bluff study area, southeast Missouri: seismic cone penetrometer test (SCPT), crosshole seismic (CH), multichannel analysis of surface waves (MASW) and refraction microtremor (ReMi). These four methods were evaluated and ranked in terms of accuracy, functionality, cost, other considerations and overall utility.
\end{abstract}

On the basis of the comparative analyses of the corresponding shear wave velocity profiles, it is concluded that MASW data are generally more reliable than SCPT data, comparable to quality ReMi data and only slightly less accurate than $\mathrm{CH}$ data. However, MASW's other advantages generally make it a superior choice over the CH, SCPT and ReMi methods for general soil classification purposes to depths of $30 \mathrm{~m}$. MASW data are much less expensive than $\mathrm{CH}$ data and can normally be acquired in areas inaccessible to drill rigs. MASW data are less expensive than SCPT data and can normally be acquired in areas inaccessible to SCPT rigs, for example on paved roadway, within bedrock and dense or rocky soil, and on steeply dipping slopes. In contrast to the MASW tool, quality ReMi data can be acquired only in areas where there are interpretable levels of "passive" acoustic energy.

\section{Introduction}

The University of Missouri-Rolla (UMR) in collaboration with the Missouri Department of Transportation (MoDOT) evaluated the following four field methods commonly used to measure and classify the shear wave velocity of soils to depths of $30 \mathrm{~m}$ in accordance with National Earthquake Hazard Reduction Program guidelines (NEHRP, 1997): crosshole seismic (CH), seismic cone penetrometer test (SCPT), multichannel analysis of surface waves (MASW) and refraction microtremor (ReMi). The four methods were field tested at forty sites in the Poplar Bluff study area, southeast Missouri. Most of the test sites lie within the MoDOT right-of-way, immediately adjacent to structures on major state highways.

These four methods were comparatively evaluated and ranked in terms of accuracy, functionality, cost, other considerations and overall utility to MoDOT. Representative shear wave velocity profiles for test site \#3 are presented in support of the evaluations and rankings. The SCPT data were processed and interpreted by dedicated MoDOT staff; all of the other geophysical data were interpreted by UMR researchers.

\section{NEHRP Shear Wave Velocities}

MoDOT routinely measures the shear wave velocity of the soils at geotechnical sites within the Mississippi Embayment because this critical parameter can be used to determine how highways and highway structures will respond to an earthquake. For the purposes of earthquake hazards investigations, the velocity of the subsurface must be measured or estimated to a depth of $30 \mathrm{~m}$. The NEHRP shear wave velocity (Vs) assigned to the subsurface at a specific site is calculated using the following formula:

$$
V s=\frac{\sum_{i=1}^{n} d_{i}}{\sum_{i=1}^{n} \frac{d_{i}}{v_{s i}}}
$$

where:

$\mathrm{Vs}=$ the assigned NEHRP shear wave velocity,

$\mathrm{v}_{\mathrm{si}}=$ the layer shear wave velocity in $\mathrm{m} / \mathrm{s}$,

$\mathrm{di}=$ the thickness of any layer (between 0 and $30 \mathrm{~m}$ ), and

$\sum_{i=1}^{n} d_{i}$ is equal to $30 \mathrm{~m}$. 


\section{Representative Shear Wave Velocity Profiles, Test Site \#3}

Crosshole Seismic $(\mathrm{CH})$ : The $\mathrm{CH}$ shear wave velocity data were acquired at $1.5 \mathrm{~m}$ depth intervals, in twinned, PVC-cased, air-filled boreholes spaced at $4.5 \mathrm{~m}$ (Figure 1). The separation between the twinned boreholes at each test depth was determined using a borehole deviation tool. These $\mathrm{CH}$ shear wave velocity data are assumed to be more reliable than the corresponding SCPT, MASW and ReMI data, and were used as a "yard stick" for evaluating the accuracy of the acquired SCPT, MASW, and ReMI shear wave velocity data.

The $\mathrm{CH}$ data are considered to be more accurate than SCPT data for several reasons. First, the $\mathrm{CH}$ source signal was higher frequency than the SCPT source signal; hence the arrival time of the $\mathrm{CH}$ shear wave pulse could be determined with greater precision. Second, SCPT field data were noisier than $\mathrm{CH}$ data; hence the arrival time of the shear wave pulse on $\mathrm{CH}$ field data could be determined with greater accuracy. Third, $\mathrm{CH}$ velocities were measured using source/ receiver separations of $4.5 \mathrm{~m}$; SCPT velocities are calculated using interval distances on the order of $1 \mathrm{~m}$. Therefore the calculation of $\mathrm{CH}$ velocities was less affected by small errors in the determination of the travel distances and/or travel times. Fourth, the direct compressional wave and direct shear wave are clearly visually separated on $\mathrm{CH}$ field data; this is not the case for SCPT field records acquired at shallow depths.

The $\mathrm{CH}$ shear wave velocity data are also considered to be more accurate than either the MASW or ReMI data for several reasons. First, $\mathrm{CH}$ shear wave travel times and travel distances are measured directly and used to compute shear wave velocities. The MASW and ReMI techniques, in contrast, measure phase-dependent surface wave velocities, and use these to estimate shear wave velocities as a function of depth. Second, MASW and ReMI shear wave velocities represent "average" velocities over lateral distances typically on the order of $30+\mathrm{m}$. Third, MASW shear wave velocities represent "average" velocities over depth intervals that increase with increasing depth of burial.

\section{Seismic Cone Penetrometer Test (SCPT):}

The SCPT shear wave velocity data were acquired by a MoDOT crew using a Hogentogler cone penetrometer unit mounted on a dedicated rig. The acquisition process was relatively straight-forward. A horizontally-polarized

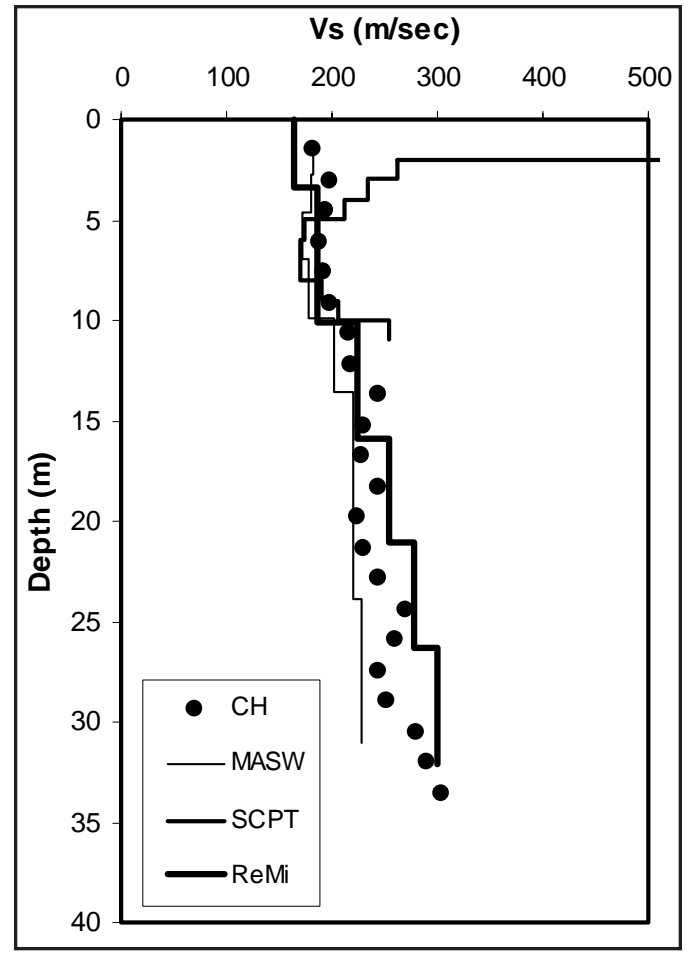

Fig. 1: $\mathrm{CH}, \mathrm{SCPT}, \mathrm{MASW}$ and ReMI shear wave velocity profiles for test site \#3.

geophone, connected to the tip of the seismic cone, was pressed into the subsurface to a depth of $1 \mathrm{~m}$. A shear wave source (hammer andblock located almost directly above the tip of the cone) was discharged twice at the surface with opposite directional impacts thereby generating two opposite polarity shear wave field records. This process was repeated as the cone was pressed into the subsurface until refusal, and halted momentarily for testing at depth intervals of $1 \mathrm{~m}$. The transit time and source/receiver separation data were used to calculate the in-situ shear wave velocity for each soil interval tested (Campanella et al., 1986). Standard CPT data were acquired simultaneously with the SCPT data. The SCPT cone only achieves its target depth of $30 \mathrm{~m}$ at one of the Poplar Bluff test sites because of high soil resistance.

\section{Multichannel Analyses of Surface Wave MASW):}

The MASW data were acquired using an engineering seismograph and 24 low-frequency $(4.5 \mathrm{~Hz})$ vertical geophones, placed at $1.5 \mathrm{~m}$ intervals (Figure 2). Acoustic energy was generated at an offset of $10 \mathrm{~m}$ using an $8 \mathrm{~kg}$ sledge hammer and metal plate.

The acquired Rayleigh wave data were processed using the Kansas Geologic Survey (KGS) software package SURFSEIS. Each set of Rayleigh wave data was transformed 
from the time domain into the frequency domain using Fast Fourier Transform techniques. These field-based data were used to generate site-specific dispersion curves for each station location. The site-specific dispersion curves generated from field-acquired Rayleigh wave data were thentransformed into vertical shear-wave velocity profiles(Park et al., 1999).

Refraction Microtremor (RTeMI): The ReMi data were acquired using 24 low-frequency $(4.5 \mathrm{~Hz})$ vertical geophones, placed at $6 \mathrm{~m}$ intervals (Figure 2). At each test site, 1 set of passive Rayleigh wave data consisting of ten field records each with a $25 \mathrm{~s}$ duration was recorded using a 24-channel engineering seismograph. ReMi field data were intentionally recorded while vehicle traffic was relatively heavy.

The acquired passive Rayleigh wave data were processed using the SeisOpt ReMi software package (Louie, 2001). Rayleigh wave data set was transformed from the time domain into a spectral energy shear wave frequency versus shear wave velocity (or slowness) presentation for each ReMi seismic setup. A dispersion curve, consisting of the lower bound of the spectral energy shear wave velocity versus frequency trend, for each setup was selected and saved. A multi-layered shear wave velocity model, consistent with the dispersion curve, was developed iteratively for each setup.

Multiple ReMi shear wave velocity profiles were generated at two test sites using geophone arrays oriented at 0, 30, 60 and 90 degrees to roadway. Arrays oriented perpendicular to the highway produced the most well defined dispersion curves and generated shear wave velocity profiles that were the most compatible with the $\mathrm{CH}$ data. The dispersion curves generated by arrays with other azimuthal orientations were not as well-defined and were therefore more difficult to interpret. ReMi shear wave velocity profiles were also generated at a test site located several $\mathrm{km}$ from any major roadways or significant cultural noise, using geophone arrays with different azimuthal orientations $(0,30$, 60, 90, 120 and 150 degrees). Analyses of these ReMi field records indicate that data quality was slightly affected by array orientation. The quality of the dispersion curves varied from poor to good depending on the orientation of the arrays. These field tests indicate that array orientation can affect ReMI results. Simple tests can be used to determine optimum orientation at any field site. Additionally, an active end-on source could be discharged to compensate for the dearth of high frequency Rayleigh wave data at remote field sites.

\section{Interpretation}

The four shear wave velocity profiles acquired at or immediately adjacent to the test site \#3 $\mathrm{CH}$ location are plotted in Figure 1. The twinned boreholes at $\mathrm{CH}$ test site \#3 encountered bedrock at a depth of approximately 34.5 $\mathrm{m}$. However, either because of obstructions or the shortness of the PVC casing, $\mathrm{CH}$ data were obtained only to a depth of $33.5 \mathrm{~m}$. MASW control at the $\mathrm{CH}$ location extends to a depth of $33.5 \mathrm{~m}$. (This depth would have been extended if a larger impact source had been used.) ReMI control extends to a depth of $32 \mathrm{~m}$. SCPT data were acquired to a depth of only $10.5 \mathrm{~m}$ because of increasing soil resistance.

The $\mathrm{CH}$ shear wave velocity profile for Site \#3 is considered to be more accurate than the MASW, ReMI or SCPT profiles. The visual inspection of the $\mathrm{CH}$ profile indicates that the shear wave velocity of soil, with minor fluctuations, increases gradually with depth of burial (from a low of about $180 \mathrm{~m} / \mathrm{s}$ to a high of about $250 \mathrm{~m} / \mathrm{s}$ at a depth of $30 \mathrm{~m}$ ). The soil at site \#3 consists almost exclusively of sand, silt and clay (Figure 2). The observed minor fluctuations in shear wave velocity are attributed to minor changes in lithology (sand, silt, clay concentrations) and grain size.

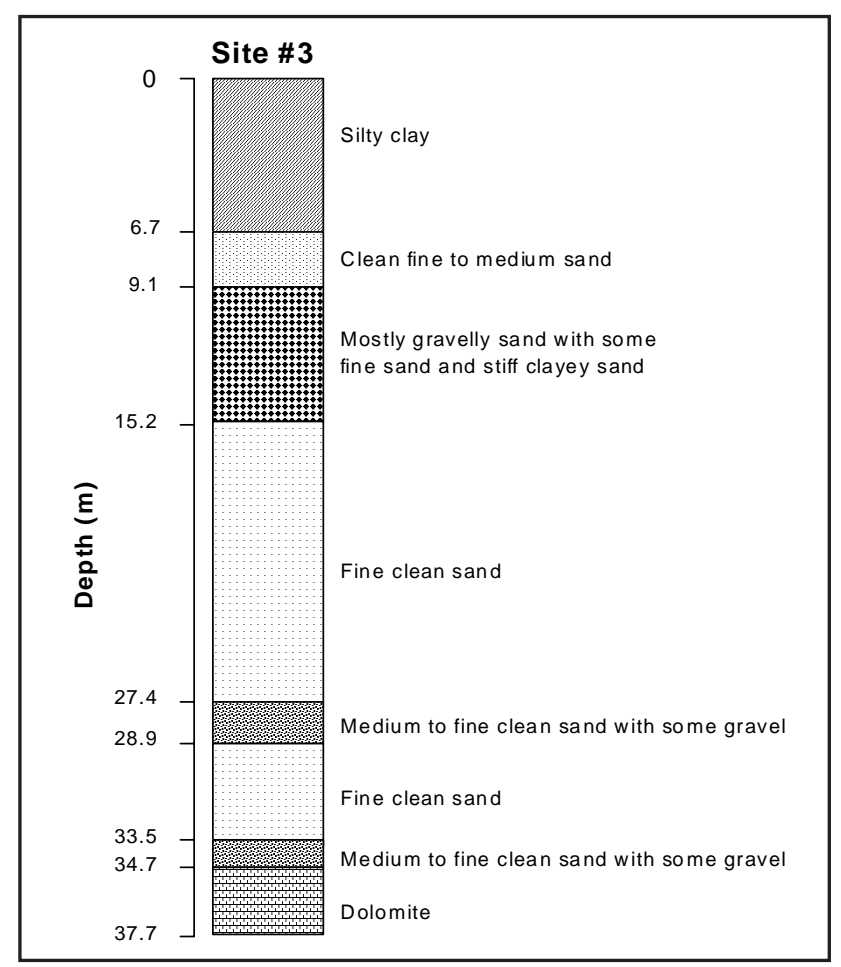

Fig. 2: Soil profile for Test Site \#3. 
The MASW shear wave profile is similar to the $\mathrm{CH}$ profile, except that MASW shear wave velocity values are consistently equal to or slightly less than the corresponding $\mathrm{CH}$ values. The MASW velocities range from about $180 \mathrm{~m} / \mathrm{s}$ to about $230 \mathrm{~m} / \mathrm{s}$ (at a depth of $30 \mathrm{~m}$ ). The ReMi shear wave profile is similar to both the $\mathrm{CH}$ and MASW profile at depths of less than $30 \mathrm{~m}$, except that the ReMi shear wave velocity values are generally equal to or slightly greater than the corresponding $\mathrm{CH}$ values. Within this depth interval, the ReMi velocities range from about $165 \mathrm{~m} / \mathrm{s}$ to about $300 \mathrm{~m} / \mathrm{s}$.

Differences between the $\mathrm{CH}$, MASW and ReMi shear wave velocities may be due to the fact that MASW and ReMi velocities are laterally and vertically averaged. Alternatively, the MASW and ReMi techniques may not be as accurate as the $\mathrm{CH}$ tool.

The SCPT shear wave velocity data correlate fairly well with the $\mathrm{CH}$, MASW and ReMI data except that the shallowest layer layer on the SCPT velocity profile was assigned, by MoDOT interpreters, an anomalously high shear wave velocity $(\sim 1200 \mathrm{~m} / \mathrm{s})$. Our experience has been that such "spikes" are not uncommon on MoDOT SCPT profiles, particularly at shallow depths. These "spikes' are not believed to be real; rather, they are assumed to result from minor inaccuracies in either the placement of the SCPT receiver or the timing of SCPT transit times. Indeed the high velocity "spikes" observed on SCPT \#1 do not correlate with zones of high tip resistance on the CPT data set (Figure 3).

\section{Comparative Analyses of Shear Wave Methods}

The four geophysical techniques used to measure and categorize shear wave velocities of soils at the Poplar Bluff test sites were evaluated in terms of accuracy, functionality, cost-effectiveness and overall utility. These parameters were evaluated from the perspective of the end user, in this case, the Missouri Department of Transportation. A discussion of the test site \#3 data follows. Similar results were obtained for the other Poplar Bluff test site data.

\section{Accuracy}

The relative accuracy of the shear wave velocity curves generated using each of the four techniques was estimated using two different approaches: average standard deviation and calculated NEHRP velocity.

In the first approach, the $\mathrm{CH}$ data were assumed to be accurate. Average deviations of the MASW, ReMI and SCPT data (relative to the $\mathrm{CH}$ data) were determined based on velocity differences at $1.5 \mathrm{~m}$ intervals over the depth ranges tested to a maximum of $30 \mathrm{~m}$. Using this approach, the MASW data set is the second most accurate with average deviations of $15 \mathrm{~m} / \mathrm{s}$. The ReMI data set is the third most accurate with an average deviations of $20 \mathrm{~m} / \mathrm{s}$. The SCPT data set is the least accurate with a standard deviation of $165 \mathrm{~m} / \mathrm{s}$. The high deviation associated with the SCPT tool is attributable to the presence of the velocity "spike".

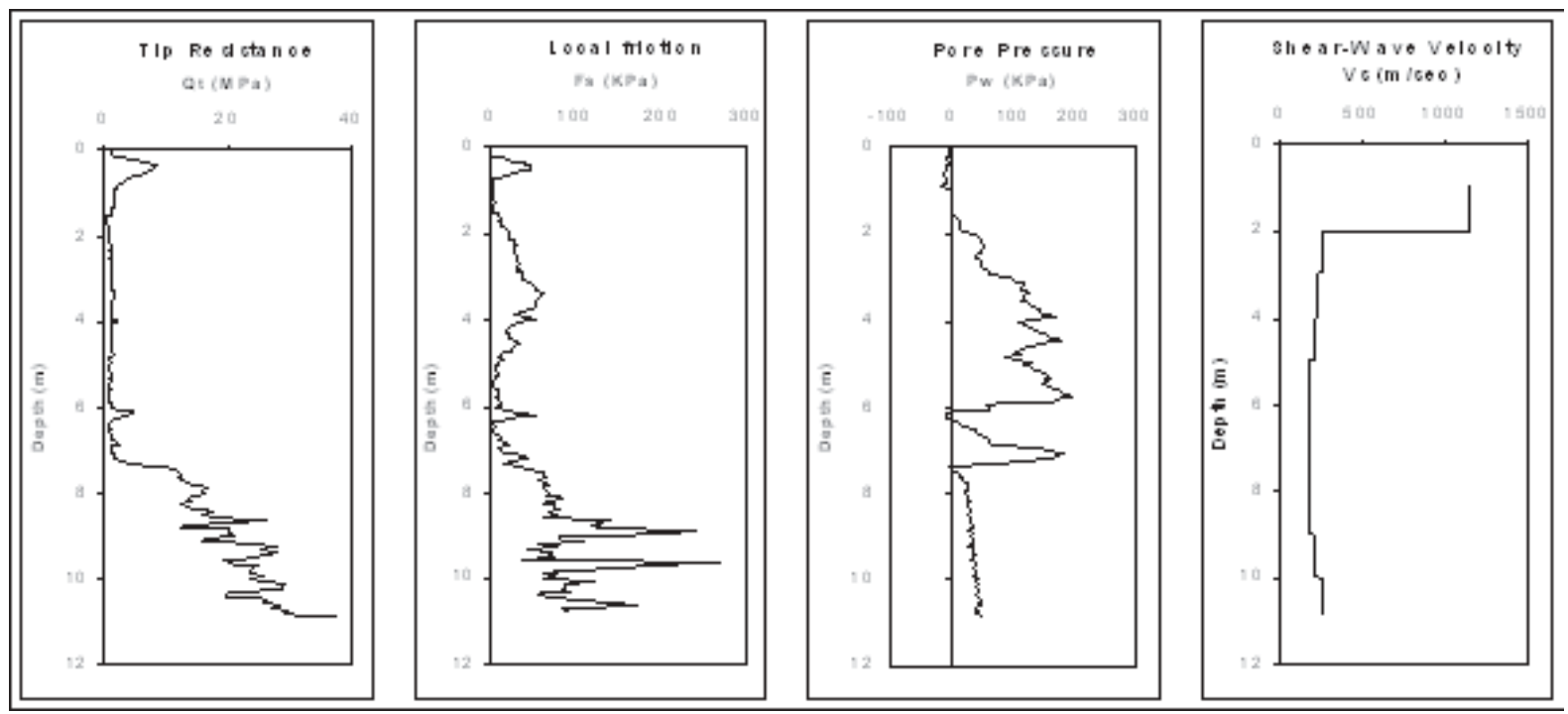

Fig. 3 : CPT and SCPT data for Test Site \#3, showing tip resistance, local friction, pore pressure and shear wave velocity. 
In the second approach, a NEHRP velocity was calculated for each profile using shear wave velocity values over the depth range tested to a maximum of $30 \mathrm{~m}$. The $\mathrm{CH}$ NEHRP velocity of $220 \mathrm{~m} / \mathrm{s}$ was assumed to be most accurate. The MASW and ReMi data sets are comparable with NEHRP velocities of $205 \mathrm{~m} / \mathrm{s}$ and $235 \mathrm{~m} / \mathrm{s}$, respectively. The SCPT data are the least accurate with a NEHRP velocity of $635 \mathrm{~m} / \mathrm{s}$ (calculated over the depth penetrated by SCPT tool).

\section{Functionality (Data Acquisition)}

Data acquisition functionality was based on each tool's capability to provide shear wave velocity control at any potential test site in the Mississippi Embayment to a depth of $30 \mathrm{~m}$ (as per NEHRP guidelines).

The MASW tool was ranked first in terms of data acquisition functionality. This tool can be deployed anywhere a $30 \mathrm{~m}$ geophone array can be laid out and a $4.5 \mathrm{~kg}$ sledge hammer (or alternate source) deployed. The low frequency MASW geophones do not need to be physically coupled to the ground so the tool can be used on any solid surface (paved or asphalt roadway, exposed rock, rocky soils, sandy soils, etc.). Data can also be acquired on sloped surfaces, beneath bridges, etc.

The ReMi tool was ranked second in terms of data acquisition functionality. The tool has all of the advantages of the MASW method, and the additional advantage of not requiring an active source. However, it was ranked second because the ReMi array is longer and requires more space, and because field testing may be required to ensure the ReMi array is aligned with a suitable source of passive wave energy. In certain instances it may not be possible to optimally orient the array because of access problems or the nature of the test site; in other situations a suitable source of passive energy may not be close enough to the test site to be of utility.

The $\mathrm{CH}$ method was ranked third in terms of data acquisition functionality because this tool can be used only at sites accessible to a drill rig. Data can be acquired on paved roadway, rock and rocky soil, but cannot be safely utilized beneath bridges and on some sloped surfaces for example. Additionally, $\mathrm{CH}$ data are normally not acquired until several days after cased drill hole completion because time is required for the grout to set. Permitting may be required.

The SCPT method was ranked fourth because it can be used only where a dedicated rig can be securely anchored. The tool cannot penetrate pavement, asphalt, rock, or rocky soil or even some stiff soils. Depth penetration at Poplar Bluff test site 3 (Figure 6) was less than $30 \mathrm{~m}$ because stiff soils were encountered. Also, great care must be taken to ensure the strike block and geophone are properly placed every time the source is discharged. The presence of "spikes" on the MoDOT SCPT data set suggest it can be difficult for a production crew to consistently exercise the care necessary to ensure placement errors do not occur.

\section{Functionality (Data Processing)}

Data processing functionality was based on the necessity for qualitative input and the potential for resultant human error.

The MASW tool was ranked first in terms of data processing functionality because all of the MASW dispersion data acquired in the Poplar Bluff area were readily "picked" during data processing, and because the results were reproducible to the extent that different processors consistently "picked" the same dispersion curve and generated essentially the same shear wave velocity profiles.

The $\mathrm{CH}$ tool has all of the advantages of the MASW method (results are reproducible to the extent that different processors consistently "picked" the same travel times and generated essentially the same shear wave velocity profiles). It was ranked second only because the processing of the $\mathrm{CH}$ data was more labor intensive than the processing of the MASW data.

The ReMI tool was ranked third in terms of data processing functionality because it was difficult to "pick" the optimum dispersion curve on some of the ReMI data acquired in the Poplar Bluff area, presumably because these data sets were not acquired using optimally-oriented geophone arrays.

The SCPT tool was ranked fourth in terms of data processing functionality because it was difficult to "pick" shear wave arrival times on records acquired at shallow depth. Additionally, perhaps because of noise, or human acquisition or processing errors, low and high velocity spikes are present on many of the SCPT shear wave velocity curves provided by MoDOT.

\section{Cost}

The ReMI tool was ranked first in terms of cost. ReMi data can be acquired at a single test site by a 2-person 
field crew in less than one hour (start to finish after arriving on-site). The equipment is portable; normally the crew and equipment are transported in a single vehicle. The data can be processed in the field on a laptop.

The MASW tool was ranked a close second in terms of cost, only because an active source is required. MASW data can be acquired at a single test site by a 2-person field crew in less than one hour (start to finish after arriving onsite). The equipment is portable; normally the crew and equipment are transported in a single vehicle. The data can be processed in the field on a laptop.

The SCPT tool was ranked third because of the high capital cost of the tool and dedicated rig and the cost of transporting the SCPT tool and rig to the field sites. Additionally, the acquisition of SCPT data at each field site took a couple of hours.

The $\mathrm{CH}$ tool was ranked fourth because of the high cost of drilling and PVC casing twinned air-filled boreholes, and acquiring borehole deviation data therein. It is also expensive to transport the drill rig and support vehicle to the test site(s). An additionally field visit is usually necessary to acquire borehole deviation and $\mathrm{CH}$ travel time data.

\section{Other Considerations}

The $\mathrm{CH}$ tool was ranked first in terms of other considerations because soil samples can be extracted from the boreholes and depth to bedrock can be accurately measured. The SCPT tool was ranked second because the simultaneously acquired CPT data can be of significant utility to geotechnical engineers. MASW and ReMi tools were ranked tied for third because they can be used to estimate variable depth to shallow bedrock.

\section{Conclusions}

Overall Utility to the Missouri Department of Transportation (MoDOT)

For the past few years, MoDOT has routinely acquired multiple SCPT data sets as part of the routine investigations of soils at highway structures or other geotechnical sites. In an effort to ensure their geotechnical investigations were as effective and efficient as possible, the SCPT tool and several available alternatives $(\mathrm{CH}$,
MASW and ReMI) were evaluated and ranked in terms of overall utility to MoDOT.

The MASW tool was ranked first in terms of overall utility. The MASW was ranked slightly ahead of or tied with the ReMi method in terms of accuracy, data acquisition and processing functionality and other considerations; it ranked slightly behind the ReMi tool in terms of cost. However, the MASW tool is rated higher overall because of the consistency of the data source and the tool's ability to consistently provide shear wave velocity control to the NEHRP specified depth of $30 \mathrm{~m}$.

The MASW tool was ranked behind the SCPT tool in terms of other considerations, but ranked ahead in terms of accuracy and processing functionality, and significantly ahead in terms of acquisition functionality and cost. The MASW tool was ranked slightly behind the $\mathrm{CH}$ tool in terms of accuracy and other considerations, but slightly ahead in terms of functionality, and significantly ahead in terms of cost.

The ReMI tool was ranked second in terms of overall utility to MoDOT. Relative to the SCPT and CH techniques, it has essentially the same advantages and disadvantages as the MASW tool.

The SCPT tool was ranked third in terms of overall utility to MoDOT. The tool has some significant limitations in that it cannot be used on hard surfaces and will not penetrate rocky or very stiff soils. However, the SCPT tool is ranked ahead of the $\mathrm{CH}$ tool, because $\mathrm{CH}$ data are prohibitively expensive to acquire if used to measure shear wave velocities at multiple locations for routine geotechnical site investigations.

\section{References}

Campanella, R.G., Robertson, P.K., and Gillespie, D., 1986, Seismic Cone Penetration Tests, Use of In-Situ Tests in Geotechnical Engineering: ASCE GSP 6, 166-130.

Louie, J.N., 2001, Faster, better, shear-wave velocity to 100 meters depth from refraction microtremor arrays: Bulletin Seismological Society of America, 85, 900-922.

NEHRP, 1997, NEHRP Recommended Provisions for Seismic Regulations for New Buildings and Other Structures, Part 1: Provisions, Building Seismic Safety Council, Washington, D. C.

Park, C.B., Miller, R.D., and Xia, J., 1999, Multichannel Analysis of Surface Waves: Geophysics, 64, 800-808. 